\title{
Regulation of Glucose Homeostasis in Humans with Denervated Livers
}

\author{
Gianluca Perseghin, ${ }^{*}$ Enrico Regalia, ${ }^{\ddagger}$ Alberto Battezzati, ${ }^{*}$ Sandro Vergani, ${ }^{*}$ Andrea Pulvirenti, ${ }^{\star}$ Ileana Terruzzi, ${ }^{*}$ \\ Dario Baratti, ${ }^{\ddagger}$ Federico Bozzetti, ${ }^{\circ}$ Vincenzo Mazzaferro, ${ }^{\ddagger}$ and Livio Luzi ${ }^{\star}$ \\ *Department of Internal Medicine, Istituto Scientifico H San Raffaele, University of Milan, 20132 Milan, Italy; and ${ }^{\ddagger}$ Liver Transplantation \\ Unit, National Cancer Institute, 20100 Milan, Italy
}

\begin{abstract}
The liver plays a major role in regulating glucose metabolism, and since its function is influenced by sympathetic/ parasympathetic innervation, we used liver graft as a model of denervation to study the role of CNS in modulating hepatic glucose metabolism in humans. 22 liver transplant subjects were randomly studied by means of the hyperglycemic/ hyperinsulinemic (study 1), hyperglycemic/isoinsulinemic (study 2), euglycemic/hyperinsulinemic (study 3) as well as insulin-induced hypoglycemic (study 4) clamp, combined with bolus-continuous infusion of $\left[3-{ }^{3} \mathrm{H}\right]$ glucose and indirect calorimetry to determine the effect of different glycemic/insulinemic levels on endogenous glucose production and on peripheral glucose uptake. In addition, postabsorptive glucose homeostasis was cross-sectionally related to the transplant age (range $=40 \mathrm{~d}-35 \mathrm{mo}$ ) in 4 subgroups of patients 2 , 6, 15, and 28 mo after transplantation. 22 subjects with chronic uveitis (CU) undergoing a similar immunosuppressive therapy and 35 normal healthy subjects served as controls. The results showed that successful transplantation was associated with fasting glucose concentration and endogenous glucose production in the lower physiological range within a few weeks after transplantation, and this pattern was maintained throughout the 28-mo follow-up period. Fasting glucose $(4.55 \pm 0.06$ vs. $4.75 \pm 0.06 \mathrm{mM} ; P=0.038)$ and endogenous glucose production $(11.3 \pm 0.4$ vs. $12.9 \pm 0.5$ $\mu \mathrm{mol} /[\mathrm{kg} \cdot \mathrm{min}] ; \boldsymbol{P}=0.029)$ were lower when compared to CU and normal patients. At different combinations of glycemic/insulinemic levels, liver transplant (LTx) patients showed a comparable inhibition of endogenous glucose production. In contrast, in hypoglycemia, after a temporary fall endogenous glucose production rose to values comparable to those of the basal condition in $\mathrm{CU}$ and normal subjects (83 \pm 5 and $92 \pm 5 \%$ of basal), but it did not in LTx subjects (66 $\pm 7 \% ; P<0.05$ vs. $C U$ and normal subjects). Fasting insulin and $C$-peptide levels were increased up to 6 mo after transplantation, indicating insulin resistance partially induced by prednisone. In addition, greater C-peptide but similar insulin levels during the hyperglycemic clamp (study 1)
\end{abstract}

Address correspondence to Livio Luzi, M.D., Amino Acid and Stable Isotope Laboratory, Istituto Scientifico H San Raffaele, via Olgettina 60, 20132 Milan, Italy. Phone: 39-2-2643-2330; FAX: 39-2-2643-3790; E-mail: luzi@rsisi.hsr.it

Received for publication 28 January 1997 and accepted in revised form 2 May 1997.

J. Clin. Invest.

(c) The American Society for Clinical Investigation, Inc. 0021-9738/97/08/0931/11 \$2.00

Volume 100, Number 4, August 1997, 931-941

http://www.jci.org suggested an increased hepatic insulin clearance in LTx as compared to normal subjects. Fasting glucagon concentration was higher 6 mo after transplantation and thereafter. During euglycemia/hyperinsulinemia (study 3), the insulininduced glucagon suppression detectable in CU and normal subjects was lacking in LTx subjects; furthermore, the counterregulatory response during hypoglycemia was blunted. In summary, liver transplant subjects have normal postabsorptive glucose metabolism, and glucose and insulin challenge elicit normal response at both hepatic and peripheral sites. Nevertheless, (a) minimal alteration of endogenous glucose production, (b) increased concentration of insulin and glucagon, and (c) defective counterregulation during hypoglycemia may reflect an alteration of the liver-CNS-islet circuit which is due to denervation of the transplanted graft. (J. Clin. Invest. 1997. 100:931-941.) Key words: liver transplantation • insulin • endogenous glucose production • insulin resistance $\bullet$ autonomic innervation

\section{Introduction}

The liver plays a major role in regulating glucose metabolism because it is the main source of endogenous glucose and the major site involved in insulin metabolism. The role of the CNS in glucoregulation has been recognized since the classical experiment of Bernard (1). In neurophysiology, the CNS uses two pathways for communicating with peripheral organs: direct neurotransmission, and release of hormones in the humoral environment. The hypothalamus is considered the crucial CNS region involved in glucoregulation $(2,3)$, and both the ventromedial $(\mathrm{VMH})^{1}$ and lateral $(\mathrm{LH})$ areas participate in this metabolic process. Adrenergic fibers originate from the VMH while cholinergic fibers start from the LH, diffusely innervating the liver (4), the pancreas (5), the adrenal medulla (6), and other gastrointestinal organs. Since all the above-mentioned organs are involved in glucose regulation, to date it has been impossible to differentiate in humans between the primary (hepatic) and the secondary (pancreatic) effects of CNS discharge on blood glucose regulation. Undoubtedly, the most immediate effects of neural control on blood glucose involve the liver (7). Stimulation of VMH causes an increase in glycogenolysis (8), in hepatic glucose output (9), and therefore in hyperglycemia. In contrast, stimulation of LH causes an activation of glycogen synthase (4), an inhibition of hepatic glucose output, and consequently a reduction of blood glucose concentration (4).

1. Abbreviations used in this paper: $\mathrm{BMI}$, body mass index; $\mathrm{CU}$, chronic uveitis; EGP, endogenous glucose production; FP, first phase of insulin secretion; $\mathrm{GH}$, growth hormone; $\mathrm{LH}$, lateral hypothalamus; LTx, liver transplant; SP, second phase of insulin secretion; VMH, ventromedial hypothalamus. 
Liver transplantation constitutes a model of denervated liver in humans. In this model, only direct neurotransmission is lacking, while neurohumoral factors are still present. Furthermore, all immunosuppressive drugs (used to avoid graft rejection) are very well known to impair to a certain extent both peripheral insulin sensitivity (10) and pancreatic function (11).

In this study we used the orthotopic liver graft as a model of liver denervation in humans. First, we exposed denervated livers to different combinations of hyperglycemia/euglycemia and hyperinsulinemia, as well as to hypoglycemia, to determine the role of both sympathetic and parasympathetic innervation on hepatic glucoregulation, and second, under the same conditions, we explored the importance of hepatic fiber interruption on the hypothalamic-hepatic-islet axis and islet hormone secretion. Third, we assessed the time-dependent variation of endogenous glucose homeostasis and hormone profile of cirrhotic patients after liver graft.

\section{Methods}

\section{Subjects}

22 liver transplant subjects were studied between July 1991 and June 1994 on 37 occasions. The livers were transplanted because of Child B-C histologically confirmed cirrhosis associated with small $(<5 \mathrm{~cm}$ single tumor or $<3 \mathrm{~cm}$ diameter for multiple tumors) hepatocellular carcinoma (12). All patients had no metastatic disease at the time of transplantation and when this study was performed. The performance status at the time of the study (Karnofsky scale) was at least 90 in each subject. No patient was on diuretics or $\beta$-blockers in the 3 mo before the study, and none had evidence of ascites or fluid retention. In detail, 10 liver transplant subjects were studied $2.3 \pm 0.2$ mo after transplantation (LTx-2), 12 after $6.0 \pm 0.4$ mo (LTx-6), 8 after $15.0 \pm 1.5 \mathrm{mo}(\mathrm{LTx}-15)$, and 7 after $28.0 \pm 2.0 \mathrm{mo}$ (LTx-28) after transplantation, for a total of 37 experiments. Table I shows the clinical and laboratory data for the patients before transplantation and after $2,6,15$, and 28 mo: they were in stable clinical and nutritional condition, and their liver function was normal, with the exception of a slight increase in alanine aminotransferase (ALT) and asparatate aminotransferase (AST). The immunosuppressive regimen after transplantation consisted of cyclosporin, azathioprine, and corticosteroid, with azathioprine discontinued after $1 \mathrm{mo}$ in all subjects. The dose of corticosteroid was progressively reduced from $20 \mathrm{mg} / \mathrm{d}$ to complete withdrawal within a year, and cyclosporin monotherapy was main- tained successfully thereafter. 22 subjects affected by chronic uveitis (CU) taking the same immunosuppressive drugs, and 35 normal healthy subjects (normal) were also studied between October 1991 and July 1995, and served as control subjects (Table I). In the 2 wk before the study, all the subjects assumed an isocaloric diet containing at least $250 \mathrm{~g}$ carbohydrates and $70-90 \mathrm{~g}$ protein per day, and on the evening before the study, they were admitted to the Department of Internal Medicine of the Istituto Scientifico H San Raffaele. All subjects were fully informed of the possible risks of the study and gave their consent. The experimental protocol was approved by the Institute Ethical Committee.

\section{Experimental protocols}

All tests were performed in the postabsorptive state after a 12-h overnight fast. At 8:00 a.m. on the morning of the study, two indwelling plastic catheters were inserted into a vein of each arm, one for the infusion of test substances (antecubital vein) and the other for periodic withdrawal of blood samples (dorsal vein of the hand cannulated in retrograde direction). The hand was kept in a heated box $\left(50-70^{\circ} \mathrm{C}\right)$ for the entire study to ensure arterialization of the venous blood. In each study protocol, a bolus $(25 \mu \mathrm{Ci})$ followed by a continuous $(0.25$ $\mu \mathrm{Ci} / \mathrm{min}$ ) infusion of HPLC-purified $\left[3-{ }^{3} \mathrm{H}\right]$ glucose (New England $\mathrm{Nu}-$ clear, Boston, MA) was administered. Blood for determination of plasma metabolites, hormone concentrations, and $\left[3-{ }^{3} \mathrm{H}\right]$ glucose-specific activity was drawn every $15 \mathrm{~min}$ during the last $30 \mathrm{~min}$ of the $2.5-\mathrm{h}$ equilibration period. While obtaining blood samples, measurements of oxygen consumption and carbon dioxide production were determined by continuous indirect calorimetry as previously described (13). After the basal equilibration period of $150 \mathrm{~min}$, one of the following experiments was begun.

Study 1: Hyperglycemic/hyperinsulinemic clamp (Fig. 1). This study was performed to determine the first (FP) and second phase (SP) of insulin secretion and the effect of combined hyperglycemia/hyperinsulinemia on endogenous glucose production (EGP). 8 liver transplant subjects (LTx: age $=45 \pm 5 \mathrm{yr}$, body mass index $[\mathrm{BMI}]=21.7 \pm 2.1$ $\mathrm{kg} / \mathrm{m}^{2}$, transplant age $=2.6 \pm 0.2 \mathrm{mo}$, prednisone $=19 \pm 1 \mathrm{mg} / \mathrm{d}, \mathrm{cy}-$ closporin $\mathrm{A}=6 \pm 1 \mathrm{mg} /[\mathrm{kg} \cdot \mathrm{d}]), 7$ subjects with chronic uveitis (CU: age $=33 \pm 4 \mathrm{yr}, \mathrm{BMI}=24.8 \pm 1.3 \mathrm{~kg} / \mathrm{m}^{2}$, prednisone $=17 \pm 3 \mathrm{mg} / \mathrm{d}$, cyclosporin $\mathrm{A}=1.0 \pm 0.5 \mathrm{mg} /[\mathrm{kg} \cdot \mathrm{d}]$, duration of immunosuppressive therapy $=4.9 \pm 1.3 \mathrm{mo}$ ), and 11 normal healthy subjects (normal: age $=27 \pm 1 \mathrm{yr}, \mathrm{BMI}=22.5 \pm 0.9 \mathrm{~kg} / \mathrm{m}^{2}$ ) underwent this experiment. Plasma glucose concentration was raised acutely and maintained at $\sim 9 \mathrm{mM}$ ( $4.5 \mathrm{mM}$ above the basal level) for $150 \mathrm{~min}$ as previously described (14). This square wave of hyperglycemia elicits the typical biphasic pattern of insulin secretion with an early burst of insulin release (FP) within the first $20 \mathrm{~min}$, followed by a gradually increasing

Table I. Clinical and Laboratory Characteristics of Study Groups

\begin{tabular}{|c|c|c|c|c|c|c|c|}
\hline & Pre-LTx & LTx-2 & LTx-6 & LTx-15 & LTx-28 & $\mathrm{CU}$ & Normal \\
\hline Subjects & 10 & 10 & 12 & 8 & 7 & 22 & 35 \\
\hline Age (yr) & $42 \pm 6$ & $47 \pm 3$ & $46 \pm 3$ & $50 \pm 2$ & $55 \pm 1$ & $42 \pm 1$ & $33 \pm 1$ \\
\hline BMI $\left(\mathrm{kg} / \mathrm{m}^{2}\right)$ & $23.7 \pm 2.0$ & $22.0 \pm 1.4$ & $24.2 \pm 1.1$ & $24.9 \pm 1.2$ & $25.8 \pm 1.1$ & $25.3 \pm 0.4$ & $23.6 \pm 0.3$ \\
\hline Transplant age (mo) & - & $2.3 \pm 0.2$ & $6.0 \pm 0.4$ & $15.0 \pm 1.5$ & $28.0 \pm 2.0$ & $7.6 \pm 2.0 *$ & - \\
\hline Cyclosporin A (mg/[kg·d $])$ & - & $8.3 \pm 1.3$ & $4.9 \pm 0.5$ & $3.6 \pm 0.2$ & $4.0 \pm 0.5$ & $4.0 \pm 0.5$ & - \\
\hline Prednisone $(\mathrm{mg} / \mathrm{d})$ & - & $18 \pm 1$ & $9 \pm 2$ & $2 \pm 1$ & - & $12 \pm 2$ & - \\
\hline Plasma albumin (g/liter) & $3.1 \pm 0.6$ & $4.3 \pm 0.1$ & $4.5 \pm 0.1$ & $4.5 \pm 0.1$ & $4.4 \pm 0.1$ & $4.8 \pm 0.3$ & $5.0 \pm 0.7$ \\
\hline AST (U/liter) & $79 \pm 5$ & $28 \pm 4$ & $56 \pm 1$ & $55 \pm 1$ & $42 \pm 1$ & $20 \pm 3$ & $19 \pm 2$ \\
\hline ALT (U/liter) & $121 \pm 7$ & $80 \pm 15$ & $137 \pm 31$ & $126 \pm 43$ & $90 \pm 43$ & $26 \pm 3$ & $24 \pm 4$ \\
\hline Plasma bilirubin (mg/dl) & $2.0 \pm 0.2$ & $1.5 \pm 0.2$ & $0.9 \pm 0.1$ & $0.9 \pm 0.1$ & $0.8 \pm 0.1$ & $0.6 \pm 0.2$ & $0.5 \pm 0.1$ \\
\hline Prothrombin time (\%) & $61 \pm 6$ & $85 \pm 3$ & $90 \pm 3$ & $91 \pm 3$ & $96 \pm 6$ & $99 \pm 2$ & $100 \pm 5$ \\
\hline
\end{tabular}

* Time duration of immunosuppressive therapy. 

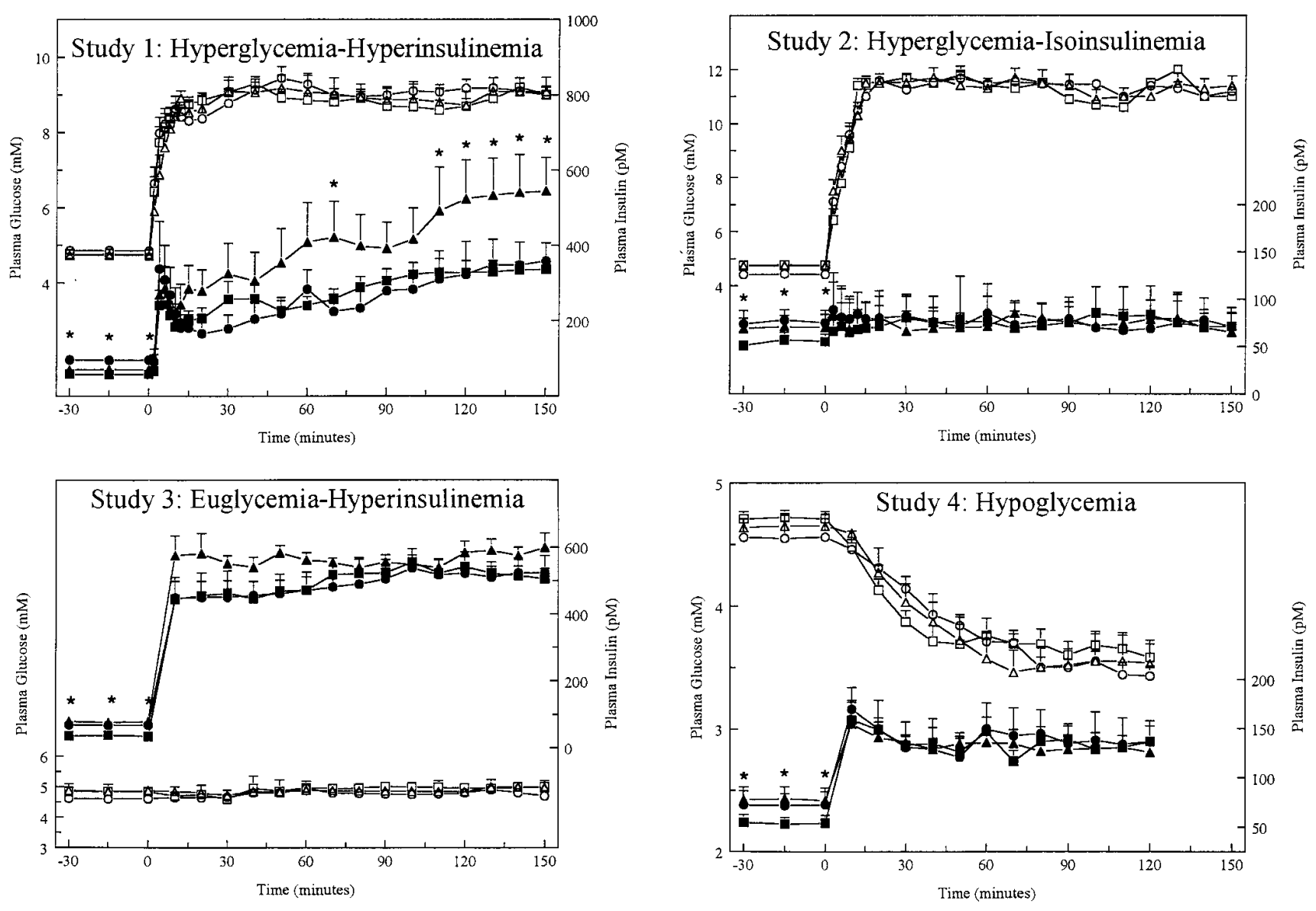

Figure 1. Experimental protocol. Liver transplant subjects and control groups were studied with the hyperglycemic/hyperinsulinemic clamp (Study 1, top left), hyperglycemic/isoinsulinemic clamp (Study 2, top right) with replacement of fasting insulin and glucagon concentrations, euglycemic/hyperinsulinemic clamp (Study 3, bottom left), and insulin-induced hypoglycemia (Study 4, bottom right). Glucose concentrations are represented with open symbols (circles, triangles, and squares, respectively, in LTx, CU, and normal subjects); insulin concentrations are represented with filled symbols (circles, triangles, and squares, respectively, in LTx, CU, and normal subjects). Data are expressed as average \pm SEM. The left $y$ axis scale is glucose concentration $(\mathrm{mM})$, the right $y$ axis scale is insulin concentration $(\mathrm{pM}) . * P=0.05$ vs. normal subjects.

phase of insulin release (SP) that persists for the duration of the study (Fig. 1, top left). Blood samples for free insulin and C-peptide were drawn every 2 min for 16 min to determine FP, then at 20 min and every 10 min thereafter to determine SP and $\left[3-{ }^{3} \mathrm{H}\right]$ glucose-specific activity. Samples for plasma glucagon, cortisol, and growth hormone (GH) were also obtained every $30 \mathrm{~min}$. Continuous indirect calorimetry was performed during the last $30 \mathrm{~min}$ of the study.

Study 2: Hyperglycemic/isoinsulinemic clamp (Fig. 1). This study was performed to determine the effect of isolated hyperglycemia with replacement of fasting insulin and glucagon concentrations on EGP. 6 LTx $\left(\right.$ age $=50 \pm 2 \mathrm{yr}, \mathrm{BMI}=24.7 \pm 1.1 \mathrm{~kg} / \mathrm{m}^{2}$, transplant age $=$ $7.8 \pm 3.3 \mathrm{mo}$, prednisone $=12 \pm 1 \mathrm{mg} / \mathrm{d}$, cyclosporin $\mathrm{A}=5.5 \pm 1.3 \mathrm{mg} /$ $[\mathrm{kg} \cdot \mathrm{d}]), 4 \mathrm{CU}\left(\right.$ age $=47 \pm 6 \mathrm{yr}, \mathrm{BMI}=23.7 \pm 0.9 \mathrm{~kg} / \mathrm{m}^{2}$, prednisone $=$ $10 \pm 1 \mathrm{mg} / \mathrm{d}$, cyclosporin $\mathrm{A}=3 \pm 1 \mathrm{mg} /[\mathrm{kg} \cdot \mathrm{day}]$, duration of immunosuppressive therapy $=10.0 \pm 2.0 \mathrm{mo}$ ) and 7 normal subjects (age $=$ $33 \pm 3 \mathrm{yr}, \mathrm{BMI}=25.0 \pm 2.2 \mathrm{~kg} / \mathrm{m}^{2}$ ) underwent this experiment. As in the previous clamp, an $\sim 11 \mathrm{mM}$ hyperglycemic clamp was performed, but endogenous insulin secretion was inhibited with somatostatin infusion $(6 \mu \mathrm{g} / \mathrm{min})$ begun $5 \mathrm{~min}$ before the start of the study. At the same time that somatostatin infusion was initiated, an infusion of insulin $(0.1 \mathrm{mU} /[\mathrm{kg} \cdot \mathrm{min}])$ and glucagon $(0.4 \mathrm{ng} /[\mathrm{kg} \cdot \mathrm{min}])$ was administered to replace their postabsorptive plasma levels (Fig. 1, top right). Blood samples for free-insulin, C-peptide, and $\left[3-{ }^{3} \mathrm{H}\right]$ glucosespecific activity were drawn every $10 \mathrm{~min}$. Samples for plasma gluca- gon and GH were also obtained every $30 \mathrm{~min}$. Continuous indirect calorimetry was performed during the last $30 \mathrm{~min}$ of the study.

Study 3: Euglycemic/hyperinsulinemic clamp (Fig. 1). This study was performed to determine the effect of isolated hyperinsulinemia on EGP and peripheral glucose disposal. $12 \mathrm{LTx}(\mathrm{age}=48 \pm 3 \mathrm{yr}$, $\mathrm{BMI}=23.9 \pm 1.2 \mathrm{~kg} / \mathrm{m}^{2}$, transplant age $=6.0 \pm 0.6 \mathrm{mo}$, prednisone $=$ $10 \pm 2 \mathrm{mg} / \mathrm{d}$, cyclosporin $\mathrm{A}=6.1 \pm 1.2 \mathrm{mg} /[\mathrm{kg} \cdot$ day $]), 6 \mathrm{CU}$ (age $=$ $46 \pm 2 \mathrm{yr}, \mathrm{BMI}=27.6 \pm 1.7 \mathrm{~kg} / \mathrm{m}^{2}$, prednisone $=10 \pm 3 \mathrm{mg} / \mathrm{d}$, cyclosporin $\mathrm{A}=1.7 \pm 0.3 \mathrm{mg} /[\mathrm{kg} \cdot \mathrm{d}]$, duration of immunosuppressive therapy $=9.0 \pm 3.1 \mathrm{mo})$, and 10 normal subjects $(\mathrm{age}=34 \pm 2 \mathrm{yr}$, BMI $=23.4 \pm 1.0 \mathrm{~kg} / \mathrm{m}^{2}$ ) underwent this experiment. The clamp was performed as previously described $(13,14)$. Insulin was infused at $1 \mathrm{mU} /$ [kg-min] to a plasma insulin concentration of $\sim 550 \mathrm{pM}$, and plasma glucose concentration was kept at $\sim 5 \mathrm{mM}$ for an additional 2.5 -h period (Fig. 1, bottom left). Blood samples for free-insulin, C-peptide, and $\left[3-{ }^{3} \mathrm{H}\right]$ glucose-specific activity were drawn every $10 \mathrm{~min}$. Samples for plasma glucagon, cortisol, and GH were also obtained every 30 min. Continuous indirect calorimetry was performed during the last 30 min of the study.

Study 4: Hypoglycemic clamp (Fig. 1). This study was performed to determine the counterregulatory response during mild hypoglycemia and its effect on EGP. 7 LTx (age $=48 \pm 5 \mathrm{yr}, \mathrm{BMI}=22.4 \pm 1.8$ $\mathrm{kg} / \mathrm{m}^{2}$, transplant age $=6.8 \pm 1.0 \mathrm{mo}$, prednisone $=10 \pm 3 \mathrm{mg} / \mathrm{d}$, cyclosporin $\mathrm{A}=5.1 \pm 1.0 \mathrm{mg} /[\mathrm{kg} \cdot \mathrm{day}]), 5 \mathrm{CU}(\mathrm{age}=45 \pm 6 \mathrm{yr}, \mathrm{BMI}=$ 
$24.8 \pm 1.8 \mathrm{~kg} / \mathrm{m}^{2}$, prednisone $=7 \pm 3 \mathrm{mg} / \mathrm{d}$, cyclosporin $\mathrm{A}=2.1 \pm 0.5$ $\mathrm{mg} /[\mathrm{kg} \cdot$ day], duration of immunosuppressive therapy $=7.9 \pm 2.7 \mathrm{mo}$ ), and 7 normal subjects (age $\left.=41 \pm 6 \mathrm{yr}, \mathrm{BMI}=23.5 \pm 1.5 \mathrm{~kg} / \mathrm{m}^{2}\right)$ underwent this experiment. A primed continuous infusion of insulin was administered at a rate of $0.3 \mathrm{mU} /[\mathrm{kg} \cdot \mathrm{min}]$ for a 2 -h period. Glucose levels were allowed to fall in response to insulin, and if plasma concentration decreased below $3.1 \mathrm{mM}$, an exogenous glucose infusion was begun and adjusted to clamp plasma glucose concentration between 3.5 and $3.7 \mathrm{mM}$ (Fig. 1, bottom right) (15). Blood samples were drawn every $10 \mathrm{~min}$ to assess plasma free insulin, C-peptide, glucagon, $\mathrm{GH}$, cortisol, and $\left[3-{ }^{3} \mathrm{H}\right]$ glucose-specific activity. Epinephrine data in $\mathrm{CU}$ and normal subjects were from historical controls (16). Due to technical reasons, 4 LTx subjects underwent only the baseline determinations.

\section{Analytical determinations}

Plasma glucose was measured bedside with a glucose analyzer (Beckman Instruments, Fullerton, CA) (13), free-insulin with an RIA (Incstar Corp., Stillwater, MN), C-peptide with an RIA using a double-antibody (13), and glucagon (13), GH (13), and cortisol (13) as previously described. Plasma for determination of epinephrine was collected into tubes containing an antioxidant agent, immediately frozen, and measured by an HPLC method as previously described $(15,16)$. Tritiated glucose-specific radioactivities were measured as previously described (13) in duplicate on the supernatants of $\mathrm{Ba}(\mathrm{OH})_{2} / \mathrm{ZnSO}_{4}$ precipitates, after total evaporation to eliminate ${ }^{3} \mathrm{H}$-water (Somogyi's method). Lactate and $\beta-\mathrm{OH}$-butyrate were measured as previously described (16)

\section{Calculations}

EGP in the basal state was determined by dividing the $\left[3-{ }^{3} \mathrm{H}\right]$ glucose infusion rate by the steady state plateau of $\left[3-{ }^{3} \mathrm{H}\right]$ glucose-specific activity achieved during the last $30 \mathrm{~min}$ of the basal period. During the experimental protocols, the rate of glucose turnover was calculated using Steele's equations in their derivative form (17). EGP was calculated by subtracting the glucose infusion rate from the rate of glucose appearance measured with the isotope tracer technique. Total body glucose uptake was determined, during the insulin/glucose infusion, by adding the rate of residual EGP to the exogenous glucose infusion rate and correcting for urinary glucose loss. The rates of glucose oxidation were calculated in the basal state and during the experiments from the nonprotein respiratory quotient (18), using the tables of Lusk (19). Nonoxidative glucose disposal was calculated by subtracting the glucose oxidation rate from the tissue glucose disposal. Protein oxidation was estimated from urinary nitrogen excretion (20). FP and SP (Fig. 1, top left) were calculated as average values over the period of 2-16 $\mathrm{min}(\mathrm{FP})$ and $60-150 \mathrm{~min}(\mathrm{SP})$, respectively. We also measured the concentrations of gluconeogenic and ketogenic metabolites in the fasting condition, and specifically lactate, pyruvate, alanine, and $\beta$-OH-butyrate. The number of subjects used for this plot was $\mathrm{LTx}=22, \mathrm{CU}=22$, normal $=35$, and the substrate levels in LTx subjects were not a function of time from transplant, since we did not find a correlation between these metabolite concentrations and time among those LTx subjects who were studied twice or more; for these subjects, the metabolite level used for the analysis was obtained as the average of all the available determinations.

\section{Statistical analysis}

All data are presented as mean \pm SEM. Statistical analysis was performed using Statview software. Comparison of different groups was performed using Student's $t$ test and ANOVA, with Fischer's posthoc testing when appropriate. Comparison of the basal and experimental states within a group was performed using the Student's $t$ test for paired data.

\section{Results}

Fasting glucose homeostasis and hormone concentrations (Table II). Fasting plasma glucose concentration and EGP were within the physiological range in liver transplant subjects; when compared to normal subjects, LTx-28 subjects showed lower plasma glucose, and LTx-2 and LTx-6 lower EGP. LTx-2, LTx-6, and CU subjects showed fasting hyperinsulinemia $(P=$ $0.05)$ and higher plasma C-peptide levels $(P=0.01)$ in comparison to normal subjects; LTx-15 and LTx-28 subjects had normal plasma insulin levels $(P=0.345$ vs. normal and $P=$ 0.05 vs. LTx-2 subjects), but increased plasma C-peptide $(P=$ 0.05 vs. normal subjects). Fasting plasma glucagon was similar in LTx-2 and CU vs. normal subjects $(P=0.125)$, but increased in LTx-6, LTx-15, and LTx-28 subjects $(P=0.01)$ when compared to normal subjects. GH levels were increased in LTx-6 vs. all the other groups $(P=0.05)$, and a trend for higher levels was observed in transplant subjects vs. CU and normal subjects $(2.1 \pm 0.4$ vs. $0.9 \pm 0.1 \mu \mathrm{g} / \mathrm{liter} ; P=0.003)$. Cortisol levels after the overnight fast were suppressed in LTx-2, LTx-6, and CU subjects, all taking $>5 \mathrm{mg} / \mathrm{d}$ prednisone, and were completely normalized when drug was suspended.

Study 1: Hyperglycemic/hyperinsulinemic clamp (Table III). Plasma glucose concentrations during the study were comparable among all groups (Fig. 1, top left). FP (0-16 min) was comparable in all groups $(P=0.55)$; SP $(90-150 \mathrm{~min})$ was similar in LTx and normal subjects, but higher in CU when compared to both LTx and normal subjects $(P=0.04)$. Surprisingly, when C-peptide was used to evaluate the endogenous insulin secretion in response to the hyperglycemic stimulus, both FP $(P=0.05)$ and SP $(P=0.002)$ were found to be

Table II. Plasma Glucose Concentration and EGP, Insulin, C-peptide, Glucagon, GH, and Cortisol Concentrations After an Overnight Fast in Subjects 2, 6, 15, and 28 mo After Liver Transplantation, in Subjects with CU, and Normal Healthy Subjects

\begin{tabular}{|c|c|c|c|c|c|c|}
\hline & LTx-2 & LTx-6 & LTx-15 & LTx-28 & $\mathrm{CU}$ & Normal \\
\hline Subjects & 10 & 12 & 8 & 7 & 22 & 35 \\
\hline Glucose (mM) & $4.66 \pm 0.11$ & $4.55 \pm 0.11$ & $4.61 \pm 0.11$ & $4.33 \pm 0.17 * 8$ & $4.72 \pm 0.11$ & $4.77 \pm 0.06$ \\
\hline $\mathrm{EGP}(\mu \mathrm{mol} /[\mathrm{kg} \cdot \mathrm{min}])$ & $10.7 \pm 1.0^{*}$ & $10.4 \pm 0.5^{*}$ & $11.6 \pm 1.2$ & $11.3 \pm 0.8$ & $12.2 \pm 0.7$ & $13.3 \pm 2.7$ \\
\hline Insulin (pM) & $68 \pm 10 *$ & $78 \pm 7$ ** & $61 \pm 6$ & $59 \pm 6$ & $71 \pm 7 *$ & $45 \pm 4$ \\
\hline C-peptide (nM) & $1.05 \pm 0.22^{\|}$ & $0.80 \pm 0.07^{\|}$ & $0.70 \pm 0.11 *$ & $0.72 \pm 0.11 *$ & $0.84 \pm 0.11^{\|}$ & $0.42 \pm 0.19$ \\
\hline Glucagon (ng/liter) & $114 \pm 7$ & $150 \pm 16^{\|}$ & $152 \pm 27^{\|}$ & $154 \pm 20^{\|}$ & $104 \pm 21$ & $86 \pm 8$ \\
\hline GH ( $\mu \mathrm{g} /$ liter $)$ & $1.1 \pm 0.2$ & $3.3 \pm 0.9^{\mathbb{I}}$ & $1.8 \pm 0.6$ & $1.6 \pm 0.7$ & $0.9 \pm 0.2$ & $0.9 \pm 0.1$ \\
\hline Cortisol (nM) & $798 \pm 31 * *$ & $926 \pm 167^{\llbracket}$ & $2014 \pm 338$ & $2277 \pm 206$ & $1427 \pm 246^{* \ddagger}$ & $2015 \pm 152$ \\
\hline
\end{tabular}

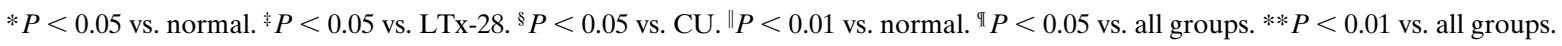


Table III. Hormone Concentrations and Glucose Metabolism During Hyperglycemic/hyperinsulinemic Clamp (Study 1)

\begin{tabular}{|c|c|c|c|c|}
\hline & & Basal & FP $0-16$ min & SP $60-150 \mathrm{~min}$ \\
\hline \multirow[t]{3}{*}{ Insulin (pM) } & $\operatorname{LTx}(n=8)$ & $96 \pm 19 *$ & $229 \pm 81$ & $285 \pm 82$ \\
\hline & $\mathrm{CU}(n=7)$ & $69 \pm 15$ & $227 \pm 43$ & $428 \pm 83^{\S}$ \\
\hline & $\operatorname{Normal}(n=11)$ & $50 \pm 9$ & $190 \pm 23$ & $292 \pm 29$ \\
\hline \multirow[t]{3}{*}{ C-peptide (nM) } & $\operatorname{LTx}(n=8)$ & $1.00 \pm 0.27^{\ddagger}$ & $1.83 \pm 0.31 *$ & $2.99 \pm 0.49^{\ddagger}$ \\
\hline & $\mathrm{CU}(n=7)$ & $0.89 \pm 0.22 *$ & $1.44 \pm 0.37 *$ & $3.35 \pm 0.72^{\ddagger}$ \\
\hline & Normal $(n=11)$ & $0.36 \pm 0.06$ & $0.81 \pm 0.16$ & $1.60 \pm 0.27$ \\
\hline \multirow[t]{3}{*}{ Glucagon (ng/liter) } & $\operatorname{LTx}(n=8)$ & $115 \pm 2$ & - & $75 \pm 21$ \\
\hline & $\mathrm{CU}(n=7)$ & $85 \pm 10$ & - & $60 \pm 7$ \\
\hline & Normal $(n=11)$ & $84 \pm 13$ & - & $66 \pm 11$ \\
\hline \multirow[t]{3}{*}{ GH $(\mu \mathrm{g} /$ liter $)$} & $\operatorname{LTx}(n=8)$ & $1.01 \pm 0.35$ & - & $5.8 \pm 2.0 *$ \\
\hline & $\mathrm{CU}(n=7)$ & $0.87 \pm 0.22$ & - & $1.9 \pm 0.7$ \\
\hline & Normal $(n=11)$ & $0.97 \pm 0.30$ & - & $1.9 \pm 1.0$ \\
\hline \multirow[t]{3}{*}{ Cortisol (nM) } & $\operatorname{LTx}(n=8)$ & $1356 \pm 756$ & - & $1107 \pm 547^{*}$ \\
\hline & $\mathrm{CU}(n=7)$ & $1697 \pm 764$ & - & $1417 \pm 510^{*}$ \\
\hline & Normal $(n=11)$ & $1907 \pm 174$ & - & $2612 \pm 386$ \\
\hline \multirow[t]{3}{*}{$\mathrm{EGP}(\mu \mathrm{mol} /[\mathrm{kg} \cdot \mathrm{min}])$} & $\operatorname{LTx}(n=8)$ & $9.9 \pm 0.9^{*}$ & $1.3 \pm 0.8$ & $1.4 \pm 1.2$ \\
\hline & $\mathrm{CU}(n=7)$ & $12.0 \pm 0.8$ & $2.9 \pm 1.2$ & $1.8 \pm 1.0$ \\
\hline & Normal $(n=11)$ & $13.8 \pm 0.5$ & $2.6 \pm 1.3$ & $2.1 \pm 1.0$ \\
\hline \multirow[t]{3}{*}{ Glucose infusion rates $(\mu \mathrm{mol} /[\mathrm{kg} \cdot \mathrm{min}])$} & $\operatorname{LTx}(n=8)$ & - & $25.1 \pm 2.3$ & $23.1 \pm 3.9$ \\
\hline & $\mathrm{CU}(n=7)$ & - & $25.9 \pm 0.9$ & $26.2 \pm 1.5$ \\
\hline & Normal $(n=11)$ & - & $25.1 \pm 1.3$ & $31.8 \pm 4.0$ \\
\hline \multirow[t]{3}{*}{ Total glucose metabolism $(\mu \mathrm{mol} /[\mathrm{kg} \cdot \mathrm{min}])$} & $\operatorname{LTx}(n=8)$ & - & $26.4 \pm 4.8$ & $24.6 \pm 5.4$ \\
\hline & $\mathrm{CU}(n=7)$ & - & $28.8 \pm 2.8$ & $28.0 \pm 1.8$ \\
\hline & Normal $(n=11)$ & - & $27.7 \pm 3.1$ & $34.0 \pm 3.5$ \\
\hline \multirow[t]{3}{*}{ Glucose oxidation $(\mu \mathrm{mol} /[\mathrm{kg} \cdot \mathrm{min}])$} & $\operatorname{LTx}(n=8)$ & - & - & $13.9 \pm 1.6$ \\
\hline & $\mathrm{CU}(n=7)$ & - & - & $19.4 \pm 2.3$ \\
\hline & Normal $(n=11)$ & - & - & $15.0 \pm 0.9$ \\
\hline \multirow[t]{3}{*}{ Nonoxidative glucose metabolism $(\mu \mathrm{mol} /[\mathrm{kg} \cdot \mathrm{min}])$} & $\operatorname{LTx}(n=8)$ & - & - & $10.7 \pm 6.5$ \\
\hline & $\mathrm{CU}(n=7)$ & - & - & $8.6 \pm 2.3$ \\
\hline & Normal $(n=11)$ & - & - & $18.9 \pm 3.1$ \\
\hline
\end{tabular}

$* P=0.05$ vs. normal. ${ }^{\ddagger} P<0.01$ vs. normal. ${ }^{\S} P=0.04$ vs. LTx and normal. EGP, glucose infusion rate, and total glucose metabolism during the first phase were calculated during the first hour $(0-60 \mathrm{~min})$.

increased not only in CU but also in LTx when compared to normal subjects. Glucagon concentration during the last hour of the experiment was comparable among groups, and the suppression from basal values was also similar $(35 \pm 18,30 \pm 4$, and $22 \pm 3 \%$ in LTx, CU and normal subjects, respectively). GH concentration increased in LTx subjects during the study, peaking at $60 \mathrm{~min}(7.6 \pm 3.1 \mu \mathrm{g} /$ liter; $P=0.04$ vs. CU and normal subjects) and keeping its concentration higher in comparison to the other groups during the last hour of the experiment. Cortisol response to hyperglycemia/hyperinsulinemia in LTx and CU was suppressed when compared to normal subjects; indeed, the percent variation was $-20,-16$, and $+37 \%$, respectively, in LTx, CU, and normal subjects $(P=0.03)$. The suppression of EGP induced by the hyperglycemic/hyperinsulinemic stimulus was similar in all study groups $(P=0.21)$. Total body glucose disposal $(P=0.08)$, glucose oxidation $(P=$ $0.11)$, and nonoxidative glucose disposal $(P=0.09)$ were also similar, even where there was a trend for lower fluxes in LTx and CU vs. normal subjects in regard to total body glucose disposal and nonoxidative glucose disposal.

Study 2: Hyperglycemic/isoinsulinemic clamp (Table IV). During the experiment, plasma glucose concentrations were kept at similar levels in all study groups (Fig. 1, top right). Endogenous insulin secretion was similarly inhibited, as illustrated by the $\mathrm{C}$-peptide concentrations $(P=0.55)$, while fasting plasma insulin concentration was efficiently replaced by means of the exogenous infusion $(P=0.77$ vs. fasting concentration) and comparable in all groups. Exogenous glucagon infusion prevented a somatostatin-induced fall in plasma concentration ( $P=0.89$ vs. fasting levels); glucagon concentration was higher in LTx vs. CU and normal subjects in both basal and study conditions $(P=0.05)$. On the contrary, GH secretion was completely and similarly suppressed in all groups. Hyperglycemia alone was similarly able to suppress EGP $(P=$ $0.47)$ and to stimulate whole body glucose uptake $(P=0.67)$; we could not detect any difference in either oxidative or nonoxidative glucose-stimulated glucose metabolism among the study groups.

Study 3: Euglycemic/hyperinsulinemic clamp (Table V). Plasma glucose concentration was kept at similar euglycemic values throughout the study (Fig. 1, bottom left). Plasma insulin concentrations were similar in all groups. Exogenous insulin infusion was able to suppress endogenous insulin secretion to the same extent in all groups. Furthermore, plasma C-pep- 
Table IV. Hormone Concentrations and Glucose Metabolism During Hyperglycemic Clamp Combined With Somatostatin Infusion and Replacement of Basal (Postabsorptive) Insulin and Glucagon (Study 2)

\begin{tabular}{|c|c|c|c|}
\hline & & Basal & $90-150 \mathrm{~min}$ \\
\hline \multirow[t]{3}{*}{ Insulin (pM) } & $\operatorname{LTx}(n=6)$ & $74 \pm 14 *$ & $77 \pm 20$ \\
\hline & $\mathrm{CU}(n=4)$ & $66 \pm 9$ & $74 \pm 16$ \\
\hline & Normal $(n=7)$ & $41 \pm 7 *$ & $65 \pm 19$ \\
\hline \multirow[t]{3}{*}{ C-peptide (nM) } & $\operatorname{LTx}(n=6)$ & $0.89 \pm 0.34 *$ & $0.22 \pm 0.08^{\ddagger}$ \\
\hline & $\mathrm{CU}(n=4)$ & $0.88 \pm 0.15^{*}$ & $0.20 \pm 0.10^{\ddagger}$ \\
\hline & Normal $(n=7)$ & $0.35 \pm 0.11$ & $0.19 \pm 0.11^{\ddagger}$ \\
\hline \multirow[t]{3}{*}{ Glucagon (ng/liter) } & $\operatorname{LTx}(n=6)$ & $183 \pm 39^{*}$ & $153 \pm 15^{*}$ \\
\hline & $\mathrm{CU}(n=4)$ & $101 \pm 12$ & $85 \pm 11$ \\
\hline & Normal $(n=7)$ & $91 \pm 20$ & $75 \pm 4$ \\
\hline \multirow[t]{3}{*}{ GH ( $\mu \mathrm{g} /$ liter $)$} & $\operatorname{LTx}(n=6)$ & $1.21 \pm 0.55$ & $0.23 \pm 0.06^{\ddagger}$ \\
\hline & $\mathrm{CU}(n=4)$ & $0.81 \pm 0.33$ & $0.18 \pm 0.06^{\ddagger}$ \\
\hline & Normal $(n=7)$ & $0.64 \pm 0.19$ & $0.19 \pm 0.04^{\ddagger}$ \\
\hline \multirow[t]{3}{*}{$\mathrm{EGP}(\mu \mathrm{mol} /[\mathrm{kg} \cdot \mathrm{min}])$} & $\operatorname{LTx}(n=6)$ & $11.0 \pm 0.8$ & $2.8 \pm 1.1$ \\
\hline & $\mathrm{CU}(n=4)$ & $12.5 \pm 0.7$ & $2.1 \pm 1.6$ \\
\hline & Normal $(n=7)$ & $13.5 \pm 0.9$ & $1.7 \pm 1.3$ \\
\hline \multirow{3}{*}{$\begin{array}{l}\text { Glucose infusion } \\
\text { rates } \\
(\mu \mathrm{mol} /[\mathrm{kg} \cdot \mathrm{min}])\end{array}$} & $\operatorname{LTx}(n=6)$ & - & $18.5 \pm 2.7$ \\
\hline & $\mathrm{CU}(n=4)$ & - & $17.5 \pm 3.6$ \\
\hline & Normal $(n=7)$ & - & $23.9 \pm 2.4$ \\
\hline \multirow{3}{*}{$\begin{array}{l}\text { Total glucose } \\
\text { metabolism } \\
(\mu \mathrm{mol} /[\mathrm{kg} \cdot \mathrm{min}])\end{array}$} & $\operatorname{LTx}(n=6)$ & - & $21.6 \pm 3.3$ \\
\hline & $\mathrm{CU}(n=4)$ & - & $19.9 \pm 5.2$ \\
\hline & Normal $(n=7)$ & - & $25.9 \pm 2.8$ \\
\hline \multirow{3}{*}{$\begin{array}{l}\text { Glucose oxidation } \\
(\mu \mathrm{mol} /[\mathrm{kg} \cdot \mathrm{min}])\end{array}$} & $\operatorname{LTx}(n=6)$ & - & $9.9 \pm 3.1$ \\
\hline & $\mathrm{CU}(n=4)$ & - & $9.0 \pm 4.7$ \\
\hline & Normal $(n=7)$ & - & $11.7 \pm 4.9$ \\
\hline \multirow{3}{*}{$\begin{array}{l}\text { Nonoxidative } \\
\text { glucose metabolism } \\
(\mu \mathrm{mol} /[\mathrm{kg} \cdot \mathrm{min}])\end{array}$} & $\operatorname{LTx}(n=6)$ & - & $11.7 \pm 6.6$ \\
\hline & $\mathrm{CU}(n=4)$ & - & $10.9 \pm 5.2$ \\
\hline & Normal $(n=7)$ & - & $14.2 \pm 4.8$ \\
\hline
\end{tabular}

$* P=0.05$ vs. normal. ${ }^{\ddagger} P<0.05$ vs. basal.

tide concentrations showed the same degree of percent suppression: $28 \pm 7,41 \pm 4$, and $33 \pm 9 \%$ in LTx, CU, and normal subjects, respectively. If hyperinsulinemia was able to suppress $\beta$ cell secretion normally in LTx subjects, it was not as efficient in suppressing $\alpha$ cell secretion: at the end of the study, plasma glucagon concentration had lowered only by $6 \pm 6 \%$ in LTx vs. $34 \pm 6$, and $43 \pm 11 \%$ in CU and normal subjects, respectively $(P=0.003)$, and this different degree of inhibition contributed to the higher plasma glucagon concentrations at the end of the study $(P=0.05)$. GH level was not significantly different in LTx vs. CU and normal subjects during the study, notwithstanding a trend for higher levels. Plasma cortisol was reduced in LTx $(P=0.05)$ and CU $(P=0.089)$ vs. normal subejcts. Hyperinsulinemia was able to suppress EGP normally in both LTx and CU when compared to normal subjects $(P=0.85)$. On the contrary, the stimulating effect of insulin on total glucose metabolism was impaired ( $P=0.01$ vs. normal subjects), and in particular, nonoxidative glucose metabolism was strongly reduced $(P=0.01)$, while glucose oxidation showed a nonsignificant reduction $(P=0.22)$.

Study 4: Hypoglycemic clamp (Table VI). Plasma glucose concentration was comparable among groups during the hypoglycemic clamp (Fig. 1, bottom right). During the exogenous insu- lin infusion, plasma glucose decreased from the fasting values to $3.44 \pm 0.05,3.55 \pm 0.16$, and $3.61 \pm 0.11 \mathrm{mM}$ in LTx, CU, and normal subjects, respectively $(P=0.44)$, during the last hour of the hypoglycemic clamp. Exogenous glucose infusion was needed in 2 of 7 LTx and in 2 of 7 normal subjects; none of the $5 \mathrm{CU}$ subjects needed exogenous glucose. Even if plasma glucose concentrations were comparable among groups at each time point, they decreased more rapidly in normal subjects; the slope of the decrement during the first 40 min of the study was significantly higher $(P=0.03)$ in normal subjects when compared to LTx subjects $(1.6 \pm 0.3,2.1 \pm 0.6$, and $2.6 \pm 0.3 \mu \mathrm{mol} /$ [kg·min], respectively, in LTx, CU, and normal subjects). On the contrary, the slope was slightly (although not significantly) higher in LTx when compared to CU and normal subjects during the second hour of the hypoglycemic clamp $(0.44 \pm 0.22$, $0.05 \pm 0.05$, and $0.22 \pm 0.11 \mu \mathrm{mol} /[\mathrm{kg} \cdot \mathrm{min}]$, respectively; $P=$ 0.154). Plasma insulin concentration was comparable among groups at all time points during the study. Plasma C-peptide was significantly higher in LTx vs. CU and normal subjects during both the first and second hour of the study; its concentration at the end of the study was similarly suppressed in terms of delta reduction $(0.46 \pm 0.08,0.46 \pm 0.09$, and $0.40 \pm 0.04$ $\mathrm{nM})$, but the percent inhibition was less evident in LTx $(P=$ $0.05)$ when compared to the control groups $(58 \pm 3,77 \pm 5$, and $72 \pm 4 \%$ in LTx, CU, and normal subjects, respectively). Plasma glucagon was higher in LTx vs. normal subjects both in the first and second hours of the study. A significant increment from fasting levels was observed during the second hour of the study only in normal subjects $(P=0.04)$. The percent increment $(15 \pm 25,38 \pm 18$, and $30 \pm 13 \%)$ and delta increment $(25 \pm 32$, $34 \pm 20$, and $26 \pm 11 \mathrm{ng} /$ liter) were not statistically different in LTx, CU, and normal subjects, respectively. Epinephrine was measured in 6 of 7 LTx subjects during the hypoglycemic clamp, and concentrations in $\mathrm{CU}$ and normal subjects were from historical controls (16). Epinephrine showed a trend for lower values in LTx vs. CU and normal subjects in basal and study conditions. The increment from the basal concentration was significant $(P=0.05)$ in all groups. The percent increment $(77,258$, and $158 \%)$ and delta increment $(760,2,670$, and 1,764 pM in LTx, CU, and normal subjects, respectively) were reduced in the transplant subjects $(P=0.03)$. Cortisol concentrations were reduced in LTx vs. CU and normal subjects both during the first and second hours. The hypoglycemia-induced increment from basal was significant in CU $(P=0.01)$ and normal subjects $(P=0.03)$, but not in LTx subjects $(P=0.3)$ during the second hour of the test. Indeed, regardless of the fact that the percent increment was not statistically different $(25 \pm 28,39 \pm 17$, and $69 \pm 38 \%)$, the delta increment $(240 \pm 249$, $844 \pm 9$, and 1,501 $\pm 599 \mathrm{nM}$ ) was impaired in LTx when compared to normal subjects $(P=0.05)$. Plasma $\mathrm{GH}$ showed a trend for higher concentrations during the study in LTx vs. CU and normal subjects, and the percent and delta increment were also slightly but not significantly higher. EGP was comparable among groups during both the first and second hour of the study. More in detail, as reflected by a slower fall of plasma glucose concentration, the percent suppression of EGP was initially $(40 \mathrm{~min})$ reduced in LTx $(29 \pm 7 \% ; P=0.04)$ and CU $(34 \pm 10 \% ; P=0.04)$ vs. normal subjects $(49 \pm 5 \%)$ (Fig. 2$)$. During the second hour of the study, EGP rose to values comparable to those of the basal conditions in CU and normal subjects ( $83 \pm 5$ and $92 \pm 5 \%$ of basal), but did not in LTx subjects (66 $\pm 7 \%$ of basal production; $P=0.05$ vs. $\mathrm{CU}$ and $P=0.03$ vs. 
Table V. Hormone Concentrations and Glucose Metabolism During Euglycemic/hyperinsulinemic Clamp (Study 3)

\begin{tabular}{|c|c|c|c|c|}
\hline & & Basal & $0-60 \mathrm{~min}$ & $90-150 \mathrm{~min}$ \\
\hline \multirow[t]{3}{*}{ Insulin (pM) } & $\operatorname{LTx}(n=12)$ & $68 \pm 5$ & $461 \pm 45$ & $521 \pm 50$ \\
\hline & $\mathrm{CU}(n=6)$ & $71 \pm 13^{*}$ & $571 \pm 33$ & $571 \pm 30$ \\
\hline & Normal $(n=10)$ & $35 \pm 8$ & $439 \pm 60$ & $474 \pm 50$ \\
\hline \multirow[t]{3}{*}{ C-peptide (nM) } & $\operatorname{LTx}(n=12)$ & $0.76 \pm 0.13 *$ & $0.57 \pm 0.09$ & $0.55 \pm 0.10$ \\
\hline & $\mathrm{CU}(n=6)$ & $0.97 \pm 0.19^{\ddagger}$ & $0.68 \pm 0.12$ & $0.57 \pm 0.09$ \\
\hline & Normal $(n=10)$ & $0.42 \pm 0.04$ & $0.29 \pm 0.05$ & $0.28 \pm 0.12$ \\
\hline \multirow[t]{3}{*}{ Glucagon (ng/liter) } & $\operatorname{LTx}(n=12)$ & $139 \pm 11$ & $122 \pm 16$ & $130 \pm 10^{\ddagger}$ \\
\hline & $\mathrm{CU}(n=6)$ & $140 \pm 10$ & $109 \pm 14$ & $92 \pm 13$ \\
\hline & Normal $(n=10)$ & $84 \pm 13$ & $66 \pm 20$ & $48 \pm 15$ \\
\hline \multirow[t]{3}{*}{$\mathrm{GH}(\mu \mathrm{g} /$ liter $)$} & $\operatorname{LTx}(n=12)$ & $3.10 \pm 0.90$ & $8.71 \pm 5.73$ & $6.74 \pm 4.13$ \\
\hline & $\mathrm{CU}(n=6)$ & $0.80 \pm 0.28$ & $1.80 \pm 1.38$ & $2.40 \pm 3.12$ \\
\hline & Normal $(n=10)$ & $0.97 \pm 0.25$ & $1.09 \pm 0.75$ & $1.74 \pm 0.71$ \\
\hline \multirow[t]{3}{*}{ Cortisol (nM) } & $\operatorname{LTx}(n=12)$ & $654 \pm 140^{*}$ & $733 \pm 414 *$ & $924 \pm 206^{\ddagger}$ \\
\hline & $\mathrm{CU}(n=6)$ & $1677 \pm 441$ & $1780 \pm 924$ & $1793 \pm 1021$ \\
\hline & Normal $(n=10)$ & $1987 \pm 209$ & $2524 \pm 567$ & $2899 \pm 668$ \\
\hline \multirow[t]{3}{*}{$\mathrm{EGP}(\mu \mathrm{mol} /[\mathrm{kg} \cdot \mathrm{min}])$} & $\operatorname{LTx}(n=12)$ & $10.3 \pm 1.7$ & $1.9 \pm 1.1$ & $1.5 \pm 0.8$ \\
\hline & $\mathrm{CU}(n=6)$ & $12.3 \pm 1.0$ & $3.3 \pm 1.1$ & $1.1 \pm 0.8$ \\
\hline & Normal $(n=10)$ & $14.5 \pm 1.3$ & $2.8 \pm 1.7$ & $1.8 \pm 0.8$ \\
\hline \multirow[t]{3}{*}{ Glucose infusion rates $(\mu \mathrm{mol} /[\mathrm{kg} \cdot \mathrm{min}])$} & $\operatorname{LTx}(n=12)$ & - & $18.9 \pm 0.9$ & $27.0 \pm 2.8^{\S}$ \\
\hline & $\mathrm{CU}(n=6)$ & - & $14.5 \pm 1.3$ & $22.4 \pm 1.3^{\S}$ \\
\hline & Normal $(n=10)$ & - & $28.1 \pm 3.9$ & $44.7 \pm 5.1$ \\
\hline \multirow[t]{3}{*}{ Total glucose metabolism $(\mu \mathrm{mol} /[\mathrm{kg} \cdot \mathrm{min}])$} & $\operatorname{LTx}(n=12)$ & - & $20.8 \pm 5.5$ & $28.5 \pm 3.6^{\S}$ \\
\hline & $\mathrm{CU}(n=6)$ & - & $17.8 \pm 1.6$ & $23.6 \pm 1.9^{\S}$ \\
\hline & Normal $(n=10)$ & - & $30.9 \pm 4.3$ & $46.6 \pm 6.4$ \\
\hline \multirow[t]{3}{*}{ Glucose oxidation $(\mu \mathrm{mol} /[\mathrm{kg} \cdot \mathrm{min}])$} & $\operatorname{LTx}(n=12)$ & - & - & $15.3 \pm 3.6$ \\
\hline & $\mathrm{CU}(n=6)$ & - & - & $14.1 \pm 2.3$ \\
\hline & Normal $(n=10)$ & - & - & $18.0 \pm 2.1$ \\
\hline \multirow[t]{3}{*}{ Nonoxidative glucose metabolism $(\mu \mathrm{mol} /[\mathrm{kg} \cdot \min ])$} & $\operatorname{LTx}(n=12)$ & - & - & $13.2 \pm 4.3^{\S}$ \\
\hline & $\mathrm{CU}(n=6)$ & - & - & $9.5 \pm 3.1^{\S}$ \\
\hline & Normal $(n=10)$ & - & - & $28.6 \pm 2.9$ \\
\hline
\end{tabular}

${ }^{*} P=0.05$ vs. normal. ${ }^{\ddagger} P=0.02$ vs. normal. ${ }^{\S} P<0.01$ vs. normal.

normal subjects) (Fig. 2). The rate of disappearance was comparable among groups and did not significantly change with respect to basal values.

\section{Discussion}

Orthotopic liver transplantation has been proven to be an effective treatment for small, unresectable hepatocellular carcinoma in patients with cirrhosis (12). The 4-yr survival rate $(75 \%)$ and the recurrence-free survival (83\%) (12) are encouraging when compared with the natural history of the untreated condition (3-yr survival rate is $25 \%$ ) (21). Moreover, patients who have hepatic carcinomas do better after transplantation than after hepatic resection $(22,23)$. These observations, along with our previous one showing that liver transplantation is effective in near-normalizing leucine and FFA metabolism (24), are generating a debate about the optimal treatment for this condition. In this regard, it is important to establish whether liver transplantation is also capable of correcting the endocrine and metabolic abnormalities typical of cirrhosis (25), and more specifically hyperinsulinemia and insulin resistance $(26,27)$, glucose intolerance, and eventually diabetes (28). Whether the liver graft is capable of restoring normal hepatic glucose production is presently unknown.
The liver is a key organ in regulating glucose metabolism. Both high insulin (29) and high glucose (30) have been shown to inhibit hepatic glucose production in humans by means of inhibition of glycogenolysis $(31,32)$, stimulation of glycogen synthesis (32), and inhibition of gluconeogenesis $(32,33)$. Both glucose and insulin cross the blood-brain barrier (34) and have specific receptors at the level of the CNS $(35,36)$, in particular in the hypothalamic site from which fibers originate, innervating visceral organs such as the liver. It is possible that part of the effect of glucose and insulin on the liver may be mediated through a neuronal and not just humoral pathway. Therefore, in this study we explored the effect of liver denervation on hepatic glucose production and insulin-mediated glucose disposal in 22 liver transplant patients (in whom the liver was surgically denervated) in stable clinical conditions with a follow-up period of $28 \mathrm{mo}$. Studies designed to assess whether and to what extent sympathetic reinnervation occurs postoperatively in the transplanted human liver found a limited capacity for regeneration of portal but not parenchymal fibers $(37,38)$. The physiological relevance of such delayed and scarce partial reinnervation is negligible. To assess whether eventual abnormalities might be due to immunosuppressive treatment, we also studied 22 subjects affected by chronic uveitis undergoing the same immunosuppressive therapy as liver transplant patients. 
Table VI. Hormone Concentrations and Glucose Metabolism During Insulin-induced Hypoglycemia (Study 4)

\begin{tabular}{|c|c|c|c|c|}
\hline & & Basal & $0-40 \mathrm{~min}$ & $60-120 \mathrm{~min}$ \\
\hline \multirow{3}{*}{ Insulin (pM) } & $\operatorname{LTx}(n=7)$ & $73 \pm 14$ & $145 \pm 27$ & $140 \pm 25$ \\
\hline & $\mathrm{CU}(n=5)$ & $78 \pm 13^{*}$ & $135 \pm 31$ & $130 \pm 27$ \\
\hline & Normal $(n=7)$ & $55 \pm 8$ & $144 \pm 15$ & $134 \pm 14$ \\
\hline \multirow[t]{3}{*}{ C-peptide (nM) } & $\operatorname{LTx}(n=7)$ & $0.81 \pm 0.14 *$ & $0.59 \pm 0.10 *$ & $0.35 \pm 0.07 *$ \\
\hline & $\mathrm{CU}(n=5)$ & $0.60 \pm 0.15$ & $0.34 \pm 0.12$ & $0.14 \pm 0.06$ \\
\hline & Normal $(n=7)$ & $0.56 \pm 0.06$ & $0.30 \pm 0.04$ & $0.16 \pm 0.03$ \\
\hline \multirow[t]{3}{*}{ Glucagon (ng/liter) } & $\operatorname{LTx}(n=7)$ & $172 \pm 26^{*}$ & $180 \pm 22 *$ & $198 \pm 26^{*}$ \\
\hline & $\mathrm{CU}(n=5)$ & $90 \pm 26$ & $81 \pm 27$ & $124 \pm 41$ \\
\hline & Normal $(n=7)$ & $87 \pm 9$ & $98 \pm 8$ & $113 \pm 13^{\S}$ \\
\hline \multirow[t]{3}{*}{ GH ( $\mu \mathrm{g} /$ liter $)$} & $\operatorname{LTx}(n=7)$ & $2.39 \pm 1.33$ & $9.34 \pm 5.06$ & $21.25 \pm 7.52$ \\
\hline & $\mathrm{CU}(n=5)$ & $0.84 \pm 0.13$ & $3.75 \pm 3.25$ & $14.39 \pm 5.88$ \\
\hline & Normal $(n=7)$ & $0.92 \pm 0.22$ & $4.01 \pm 1.25$ & $9.22 \pm 3.21$ \\
\hline \multirow[t]{3}{*}{ Epinephrine (pM) } & $\operatorname{LTx}(n=6)$ & $982 \pm 302$ & - & $1742 \pm 554^{\S}$ \\
\hline & $\mathrm{CU}(n=5)$ & $1031 \pm 243$ & - & $3701 \pm 942^{\S}$ \\
\hline & Normal $(n=7)$ & $1113 \pm 325$ & - & $2877 \pm 431^{\S}$ \\
\hline \multirow[t]{3}{*}{ Cortisol (nM) } & $\operatorname{LTx}(n=7)$ & $949 \pm 326$ & $824 \pm 236^{*}$ & $1189 \pm 370^{\ddagger}$ \\
\hline & $\mathrm{CU}(n=5)$ & $2171 \pm 990$ & $2431 \pm 1117$ & $3016 \pm 1000^{\S}$ \\
\hline & Normal $(n=7)$ & $2191 \pm 240$ & $2304 \pm 155$ & $3692 \pm 348^{\S}$ \\
\hline \multirow[t]{3}{*}{$\mathrm{EGP}(\mu \mathrm{mol} /[\mathrm{kg} \cdot \mathrm{min}])$} & $\operatorname{LTx}(n=7)$ & $11.9 \pm 1.5$ & $8.4 \pm 1.3$ & $7.9 \pm 1.5$ \\
\hline & $\mathrm{CU}(n=5)$ & $11.4 \pm 0.7$ & $7.5 \pm 1.3$ & $9.5 \pm 1.0$ \\
\hline & Normal $(n=7)$ & $10.6 \pm 0.3$ & $5.3 \pm 0.5$ & $9.7 \pm 0.3$ \\
\hline \multirow[t]{3}{*}{ Rate of disappearance $(\mu \mathrm{mol} /[\mathrm{kg} \cdot \mathrm{min}])$} & $\operatorname{LTx}(n=7)$ & $11.9 \pm 1.5$ & $11.9 \pm 1.2$ & $9.4 \pm 1.5$ \\
\hline & $\mathrm{CU}(n=5)$ & $11.4 \pm 0.7$ & $11.4 \pm 1.0$ & $9.0 \pm 1.0$ \\
\hline & Normal $(n=7)$ & $10.6 \pm 0.3$ & $10.0 \pm 1.2$ & $10.6 \pm 0.4$ \\
\hline
\end{tabular}

${ }^{*} P=0.05$ vs. normal. ${ }^{\ddagger} P=0.05$ vs. $\mathrm{CU}$ and normal. ${ }^{\S} P=0.05$ vs. basal. Epinephrine concentrations in $\mathrm{CU}$ and normal subjects were from historical controls (16).

The results of our study show that successful liver transplantation is characterized by fasting glucose concentration and fasting EGP in the lower physiological range throughout the 28-mo follow-up period (Table II). In fact, statistical analysis comparing data in LTx (subjects with denervated liver) with $\mathrm{CU}$ and normal subjects (normally innervated liver) demonstrated reduced fasting glucose concentrations in transplant subjects vs. control groups $(4.55 \pm 0.06$ vs. $4.75 \pm 0.06 \mathrm{mM} ; P=$ $0.038)$, and consensual data were observed for EGP $(11.3 \pm 0.4$ vs. $12.9 \pm 0.5 \mu \mathrm{mol} /[\mathrm{kg} \cdot \mathrm{min}] ; P=0.029)$. Lower plasma glucose levels and hepatic glucose production were described during the first day after liver transplantation or surgical denervation in pigs (39) and rats (40), but to our knowledge this is the first report of an unbalanced regulation of EGP in human subjects after liver transplantation. This occurred despite increased glucagon, which has been shown to normally stimulate hepatic glucose production in denervated liver in the dog model (41) and presumably reflects increased insulin (Table II). To investigate the effects of the variables glucose and insulin on EGP during different experimental settings, we studied the effect of combined hyperglycemia/hyperinsulinemia (Fig. 1, top left), hyperglycemia alone (Fig. 1, top right), and hyperinsulinemia alone (Fig. 1, bottom left) in subgroups of LTx subjects. As can be seen in Tables III, IV, and V in all these experimental conditions, LTx subjects showed comparable inhibitory patterns of EGP, demonstrating an intact capacity to inhibit EGP in conditions of physiologic hyperglycemia and/or hyperinsulinemia. In contrast, when plasma glucose concentration was re- duced during a hypoglycemic clamp (Fig. 1, bottom right, and Table VI), some differences were detectable. In fact, during the first $40 \mathrm{~min}$ of the hypoglycemic clamp, EGP was less suppressed and the insulin-induced glucose fall was slower than in normal subjects (Fig. 2); this was probably due to the peripheral insulin resistance rather than to an hepatic effect, since the CU group (on the same immunosuppressive therapy) showed an identical trend. During the second hour of the test, EGP kept falling in LTx subjects, rather than showing an opposite

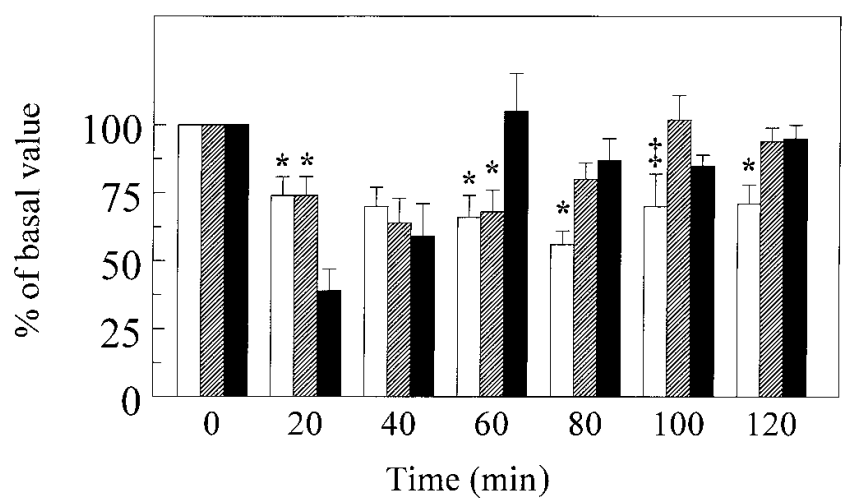

Figure 2. EGP during the hypoglycemic clamp (study 4) in LTx, CU, and normal subjects. EGP is given as percent basal value (time $=0$ ). Data are represented as average \pm SEM. $* P=0.05$ vs. normal sub-

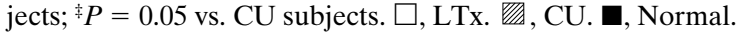


trend to rebound towards the fasting rate values, as shown by normal and CU subjects (Fig. 2). The inclusion of a control group of subjects on the same immunosuppressive therapy allowed us to reject the hypothesis that the above described alterations might be due to prednisone or cyclosporin therapy. Where hormones were concerned, LTx subjects showed several differences from the hormonal pattern of normal subjects eventually capable of inducing an altered regulation of EGP. Fasting insulin and C-peptide levels were significantly increased up to 6 mo after transplantation and still slightly increased thereafter. This indicates an insulin-resistant state (confirmed by fasting hyperinsulinemia), which is at least partially induced by prednisone. The fact that CU subjects (on the same immunosuppressive therapy) showed a similar reduction of insulin action and that the withdrawal of prednisone caused a normalization of insulin levels support this hypothesis. Furthermore, C-peptide levels were still higher in LTx-15 and LTX-28 in comparison to normal subjects. This observation suggests an increased islet $\beta$ cell secretion (42), eventually combined with an increased insulin clearance at the liver site. The same impression is derived from analysis of the hyperglycemic clamp. As can be seen in Table III, insulin concentrations were comparable to normal subjects during both FP and SP, while the corresponding C-peptide concentrations were higher than in normal subjects. The increment in hepatic insulin clearance in liver transplant subjects may be due to denervation of the graft, changes in hepatic blood flow (43), or minimally impaired liver function (Table I). One should also consider the alternative possibility that C-peptide kinetics may be different than in controls. In this regard, during euglycemia/ hyperinsulinemia the fasting $\mathrm{C}$-peptide concentration was still higher in LTx subjects, but its suppression was comparable to normal subjects, demonstrating that autoinhibition of insulin secretion is normally operating in humans lacking the liverhypothalamus-islet circuit. To note, a defect in autoinhibition of insulin secretion has been shown in cirrhotic patients (27). The glucagon concentration was normal 2 mo after transplantation, but consistently higher thereafter (Table II). The possibility that such alteration may be due to immunosuppressive therapy is excluded by the fact that the LTx-2 (with the highest prednisone dose) and CU subjects showed normal plasma glucagon concentrations, while LTx-15 and LTx-28 subjects (with the lowest dose or not receiving prednisone at all, respectively) showed the highest concentration of glucagon. During euglycemia/hyperinsulinemia, the insulin-induced glucagon suppression detectable in CU and normal subjects, was lacking in LTx subjects. Since we excluded that such hormonal abnormalities may be due to the effect of immunosuppressive drugs, we believe that the organ denervation is responsible for them. It has been suspected for a long time that the liver may exert control over endocrine pancreatic functions neuromodulating the secretions of the islets of Langerhans $(44,45)$. Anatomically, this control may be exercised through several types of sensors in the region of the portal vein and within the liver, which send vagal afferences (46-49) to the hypothalamus. Some of these hepatic vagal-mediated sensors are glucose responsive (5053); a primacy of these liver glucosensors in the sympathetic response to progressive hypoglycemia has been demonstrated, and in particular they may play an even greater role as the rate of fall in glycemia is less (54), exactly the case in liver transplant subjects during study 4 . Physiologically, a signal from the periphery would drive the CNS to modulate the islet of
Langerhans response. Therefore, the lack of liver innervation may be responsible for the alteration of endocrine pancreas secretions in response to physiological stimuli. In addition, we found that the epinephrine response to the insulin-induced hypoglycemia was blunted in percent or delta-increment units, suggesting that hepatic afferent nerves are also functionally implicated in hepatoadrenal counterregulatory reflex mechanisms during hypoglycemia, an observation previously reported in dogs $(49,54)$.

An additional finding characterizing LTx subjects was a trend for higher $\mathrm{GH}$ concentration with respect to both $\mathrm{CU}$ and normal subjects. Increased GH secretion rates, impaired GH clearance, and reduced serum IGF-I were found in subjects with chronic liver disease (55). We could not assess whether higher GH concentration in LTx subjects had a pretransplant origin (cirrhosis-linked), not correctable with the transplant, or a transplant-related genesis. Fasting cortisol concentration was also abnormal up to 6 mo after transplant. Its concentration was suppressed because of the feedback inhibition due to pharmacological therapy; when prednisone was withdrawn, fasting cortisol increased to normal values.

The immunosuppressive therapy is also responsible for the insulin resistant state mirrored by the reduced glucose metabolism rate measured during the euglycemic/hyperinsulinemic clamp (Table V); we previously showed that prednisone is the main determinant of insulin resistance in LTx subjects, and that cyclosporin, at that dose, cannot account for the defective insulin-stimulated glucose metabolism (24). We observed in this study that 5 of the 12 LTx subjects who were not on prednisone but only on cyclosporin treatment did not show any resistance to insulin action when compared to normal subjects $(43.0 \pm 3.1 \mathrm{vs} .46 .6 \pm 6.4 \mu \mathrm{mol} /[\mathrm{kg} \cdot \mathrm{min}])$, reverting the defect to the level of the nonoxidative glucose metabolism.

To assess whether the previously discussed hormonal imbalance affects other metabolic pathways which take place at the liver site, we also measured the concentrations of other metabolites: lactate, pyruvate, alanine, and $\beta-\mathrm{OH}$-butyrate. Fasting concentrations of tricarbon gluconeogenic precursors such as alanine $(216 \pm 12$ vs. $310 \pm 18 \mu \mathrm{M}$ in LTx and CU + normal subjects; $P<0.0001)$ and lactate $(595 \pm 38$ vs. $750 \pm 53 \mu \mathrm{M}$ in LTx and CU + normal subjects; $P=0.018$ ), but not pyruvate, were found to be reduced in subjects with denervated liver. Glucagon induces stimulation of hepatic gluconeogenesis (56-58), and even small increments of its concentration may induce a relative increase in the gluconeogenic pathway (32). Whether the hyperglucagonemia observed in our LTx subjects actively induces stimulation of gluconeogenic flux was not directly assessed during this study, and we could not find a correlation between the levels of plasma glucagon and alanine or lactate concentrations. On the contrary, $\beta-\mathrm{OH}$-butyrate concentration was higher in LTx subjects $(136 \pm 20 \mu \mathrm{M})$ than in $\mathrm{CU}+$ normal subjects $(97 \pm 12 \mu \mathrm{M} ; P=0.05)$, and a correlation between fasting plasma glucagon and $\beta-\mathrm{OH}$-butyrate $(\mathrm{R}=$ $0.51, P=0.0018$ ) was found in LTx but not in control groups ( $\mathrm{R}=-0.079, P=0.69)$, suggesting a relationship between the two parameters. This more gluconeogenic and ketogenic profile of hepatic glucose metabolism in denervated livers is in accordance with previous data in animals (41).

In summary, liver transplant subjects are characterized by normal glucose metabolism in the fasting condition, and glucose and/or insulin challenge elicits normal regulation of glucose metabolism at both hepatic and (after prednisone withdrawal) 
peripheral sites. Nevertheless, (a) subminimal alteration of EGP, $(b)$ increased concentration of insulin, glucagon, and eventually $\mathrm{GH}$, and $(c)$ defective counterregulatory response during hypoglycemia may reflect an alteration of the liverCNS-endocrine pancreas and adrenal medulla circuit due to the afferent and/or efferent denervation of the transplanted organ. The metabolic impact of this alteration on the regulation of glucose metabolism is apparently negligible, because the hormonal/substrate milieu finds a new functionally efficient balance which compensates for the absence of neuromodulation of the metabolic pathways. Whether the above described abnormalities and the lower gluconeogenic precursor and higher ketone body concentrations have a deleterious effect after longer time will be a matter for future investigations.

\section{Acknowledgments}

This work was supported by the Istituto Scientifico H San Raffaele and by a grant from the National Cancer Institute, Milan, Italy. Dr. G. Perseghin was supported by a postdoctoral fellowship from the Juvenile Diabetes Foundation International (394130), and previously by a research training award from the Istituto Scientifico H San Raffaele. Dr. L. Luzi was supported by a grant award from the Juvenile Diabetes Foundation International (194153). Work performed at the National Cancer Institute was supported by the Associazione Italiana Ricerca Cancro.

\section{References}

1. Bernard, C. 1849. Chiens rendus diabetiques. C.R. Seances Soc. Biol. Fil. 1:60-78.

2. Havel, P.J., and J.G. Taborsky. 1989. The contribution of autonomic nervous system to changes of glucagon and insulin secretion during hypoglycemic stress. Endocr. Rev. 10:332-350.

3. Rohner-Jeanrenaud, F., E. Bobbioni, E. Jonescu, J.F. Sauter, and B. Janrenaud. 1983. Central nervous system regulation of insulin secretion. II. CNSintegrated afferent and efferent signals that modulate insulin secretion during periods of plenty and scarcity. Adv. Metab. Disord. 10:198-201.

4. Shimazu, T. 1983. Reciprocal innervation of the liver: its significance in metabolic control. Adv. Metab. Disord. 10:355-384.

5. Miller, R.E. 1981. Pancreatic neuroendocrinology: peripheral neural mechanisms in the regulation of the islets of Langerhans. Endocr. Rev. 2:471-490.

6. Smith, G.P., J. Gibbs, A.J. Strohmayer, A.W. Root, and P.E. Stokes. 1973. Effect of 2-deoxy-D-glucose on insulin response to glucose in intact and adrenalectomized monkeys. Endocrinology. 92:750-758.

7. Benzo, C.A. 1983. The hypothalamus and blood glucose regulation. Life Sci. 32:2509-2515.

8. Shimazu, T., and A. Amakawa. 1968. Regulation of glycogen metabolism in liver by the autonomic nervous system. III. Differential effects of sympathetic nerve stimulation and of catecholamine on liver phosphorylase. Biochim. Biophys. Acta. 165:349-356.

9. Jarhult, J., B. Falck, S. Ingemansson, and A. Nobin. 1979. The functional importance of sympathetic nerves to the liver and endocrine pancreas. Ann. Surg. 189:96-100.

10. Pagano, G., P. Cavallo-Perin, M. Cassader, A. Bruno, A. Ozzello, P. Masciola, A.M. Dall'Olmo, and B. Imbimbo. 1983. An in vivo and in vitro study of the mechanism of prednisone-induced insulin resistance in healthy subjects. J. Clin. Invest. 72:1814-1820.

11. Nielsen, J.H., T. Mandrup-Poulsen, and J. Nerup. 1986. Direct effect of CyA on human pancreatic $\beta$-cell. Diabetes. 35:1049-1052.

12. Mazzaferro, V., E. Regalia, R. Doci, S. Andreola, A. Pulvirenti, F. Bozzetti, F. Montalto, M. Ammatuna, A. Morabito, and L. Gennari. 1996. Liver transplantation for the treatment of small hepatocellular carcinomas in patients with cirrhosis. N. Engl. J. Med. 334:693-699.

13. Luzi, L., A. Secchi, F. Facchini, A. Battezzati, C. Staudacher, D. Spotti, R. Castoldi, G. Ferrari, V. Di Carlo, and G. Pozza. 1990. Reduction of insulin resistance by combined kidney-pancreas transplantation in type 1 (insulin-dependent) diabetic patients. Diabetologia. 33:549-556.

14. De Fronzo, R.A., J.D. Tobin, and R. Andres. 1979. Glucose clamp technique: a method for quantifying insulin secretion and resistance. Am. J. Physiol. 6:E214-E223.

15. Battezzati, A., L. Luzi, G. Perseghin, E. Bianchi, D. Spotti, A. Secchi, S. Vergani, V. Di Carlo, and G. Pozza. 1994. Persistence of counter-regulatory ab- normalities in insulin-dependent diabetes mellitus after pancreas transplantation. Eur. J. Clin. Invest. 24:751-758.

16. Luzi, L., A. Battezzati, G. Perseghin, E. Bianchi, S. Vergani, A. Secchi, E. La Rocca, C. Staudacher, D. Spotti, G. Ferrari, et al. 1992. Lack of feed-back inhibition of insulin secretion in denervated human pancreas. Diabetes. 41: 1632-1639.

17. Steele, R. 1959. Influence of glucose loading and of injected insulin on hepatic glucose output. Ann. NY Acad. Sci. 82:420-430.

18. Frayn, K.N. 1983. Calculation of substrate oxidation rates in vivo from gaseous exchange. J. Appl. Physiol. 55:628-634.

19. Lusk, G. 1924. Animal calorimetry: analysis of the oxidation of mixtures of carbohydrate and fat. J. Biol. Chem. 59:41-42.

20. Hawk, P.D. 1947. Kjedhal method. In Practical Physiological Chemistry. 12th ed. Blakiston, Toronto. 814-822.

21. Barbara, L., G. Benzi, S. Gaiani, F. Fusconi, G. Zironi, S. Siringo, A Rigamonti, C. Barbara, W. Grigioni, and A. Mazziotti. 1992. Natural history of small untreated hepatocellular carcinoma in cirrhosis: a multivariate analysis of prognostic factors of tumor growth rate and patient survival. Hepatology. 16: 132-137.

22. Ringe, B., R. Pichlmayr, C. Wittekind, and G. Tusch. 1991. Surgical treatment of hepatocellular carcinoma: experience with liver resection and transplantation in 198 patients. World J. Surg. 15:270-285.

23. Iwatsuki, S., T.E. Starzl, D.G. Sheahan, I. Yokoyama, A.J. Demetris, S. Todo, A.G. Tzakis, D.H. Van Thiel, B. Carr, R. Selby, and J. Madariaga. 1991. Hepatic resection versus transplantation for hepatocellular carcinoma. Ann. Surg. 214:221-228.

24. Luzi, L., G. Perseghin, E. Regalia, L. Piceni Sereni, A. Battezzati, D. Baratti, E. Bianchi, I. Terruzzi, H. Hilden, L.C. Groop, et al. 1997. Metabolic effects of liver transplantation in cirrhotic patients. J. Clin. Invest. 99:692-700.

25. Petrides, A.S., and R.A. De Fronzo. 1989. Glucose metabolism in cirrhosis: a review with some perspective for the future. Diabetes Metab. Rev. 5: 691-709.

26. Selberg, O., W. Burchert, J. van der Hoff, G.J. Meyer, H. Hundeshagen, E. Radoch, H.-J. Balks, and M.J. Müller. 1993. Insulin resistance in liver cirrhosis. Positron-emission tomography scan analysis of skeletal muscle glucose metabolism. J. Clin. Invest. 91:1897-1902.

27. Cavallo-Perin, P., M. Cassader, C. Bozzo, A. Bruno, P. Nuccio, A.M. Dall'Olmo, M. Marucci, and G. Pagano. 1985. Mechanism of insulin resistance in human liver cirrhosis. Evidence of a combined receptor and postreceptor defect. J. Clin. Invest. 75:1659-1665.

28. Megyesi, C., E. Samols, and V. Marks. 1967. Glucose tolerance and diabetes in chronic liver disease. Lancet. 2:1055-1061.

29. Rizza, R., L.J. Mandarino, and E. Gerich. 1981. Dose-response characteristics for effects of insulin on production and utilization of glucose in man. Am. J. Physiol. 240:E630-E639.

30. De Fronzo, R.A., and E. Ferrannini. 1987. Regulation of hepatic glucose metabolism in humans. Diabetes Metab. Rev. 3:415-459.

31. De Fronzo, R.A., E. Ferrannini, R. Hendler, P. Felig, and J. Wharen. 1983. Regulation of splanchnic and peripheral glucose uptake by insulin and hyperglycemia in man. Diabetes. 32:35-45.

32. Roden, M., G. Perseghin, K.F. Petersen, J.-H. Hwang, G.W. Cline, K Gerow, D.L. Rothman, and G.I. Shulman. 1996. The roles of insulin and glucagon in the regulation of hepatic glycogen synthesis and turnover in humans. $J$. Clin. Invest. 97:642-648.

33. Rossetti, L., D. Smith, G.I. Shulman, D. Papachristou, and R.A. De Fronzo. 1987. Correction of hyperglycemia with phlorizin normalizes tissue sensitivity to insulin in diabetic rats. J. Clin. Invest. 79:1510-1515.

34. Woods, S.C., and D. Porte Jr. 1977. Relationship between plasma and cerebrospinal fluid insulin levels in dogs. Am. J. Physiol. 233:E331-E334.

35. Grunstein, H.S., D.E. James, L.H. Storlien, G.A. Smythe, and E.W. Kraegen. 1985. Hyperinsulinemia suppresses glucose utilization in specific brain regions: in vivo studies using the euglycemic clamp in the rat. Endocrinology. 116:604-610.

36. Schwartz, M.W., D.P. Figlewicz, D.G. Baskin, S.C. Woods, and D. Porte Jr. 1992. Insulin in the brain: a hormonal regulator of energy balance. Endocr. Rev. 13:387-414.

37. Boon, A.P., S.G. Hubscher, J.A. Lee, J.E. Hines, and A.D. Burt. 1992. Hepatic re-innervation following orthotopic liver transplantation in man. $J$. Pathol. 167:217-222.

38. Kjaer, M., J. Jurlander, S. Keiding, H. Galbo, P. Kirkegaard, and E. Hage. 1994. No reinnervation of hepatic sympathetic nerves after liver transplantation in human subjects. J. Hepatol. 20:97-100.

39. Hansen, C.P., S. Boesby, and P. Kirkegaard. 1991. Glucose homeostasis after orthotopic liver transplantation in the pig. Transplantation (Baltimore). 51:587-589.

40. Lindfeldt, J., B. Ahren, and T. Holmin. 1993. Glucose homeostasis after peri-arterial hepatic denervation in partially hepatectomized rats. Res. Exp. Med. 193:397-405.

41. Wada, M., C.C. Connolly, C. Tarumi, D.W. Neal, and A.D. Cherrington. 1995. Hepatic denervation does not significantly change the response of the liver to glucagon in conscious dogs. Am. J. Physiol. 268:E194-E203.

42. Krentz, A.J., B. Dousset, D. Mayer, P. McMaster, J. Buckels, R. Cramb, 
J.M. Smith, and M. Nattrass. 1993. Metabolic effects of cyclosporin A and FK 506 in liver transplant recipients. Diabetes. 42:1753-1759.

43. Navasa, M., F. Feu, J.C. Garcia-Pagan, W. Jimenez, J. Llach, A. Rimola, J. Bosch, and J. Rodes. 1993. Hemodynamic and humoral changes after liver transplantation in patients with cirrhosis. Hepatology. 17:355-360.

44. Lautt, W.W. 1983. Afferent and efferent neural roles in liver function. Prog. Neurobiol. (Oxf.). 21:323-348.

45. Niijima, A. 1981. Visceral afferents and metabolic function. Diabetologia. 20(Suppl.):325-330.

46. Okazaki, H., K. Tanaka, H. Nagase, and S. Inoue. 1993. Modulation of insulin secretion by hepatic vagotomy in cirrhotic rats. Physiol. Behav. 53:521-525.

47. Tanaka, K., S. Inoue, S. Saito, H. Nagase, and Y. Takamura. 1993. Hepatic vagal amino acid sensors modulate amino acid induced insulin and glucagon secretion in the rat. J. Auton. Nerv. Syst. 42:225-231.

48. Carobi, C., and F. Magni. 1981. The afferent innervation of the liver: a horseradish peroxidase study in the rat. Neurosci. Lett. 23:269-274.

49. Lamarche, L., N. Yamaguchi, and F. Peronnet. 1995. Hepatic denervation reduces adrenal catecholamine secretion during insulin-induced hypoglycemia. Am. J. Physiol. 268:R50-R57.

50. Novin, D., D.A. Vanderweele, and M. Rezeck. 1973. Infusion of 2-deoxyD-glucose into the hepatic-portal system causes eating: evidence for peripheral glucoreceptors. Science (Wash. DC). 181:858-860.

51. Russek, M. 1963. Participation of hepatic glucoreceptors in the control of food intake. Nature (Lond.). 197:79-80.

52. Schmitt, M. 1973. Influences of hepatic portal receptors on hypothalamic feeding and satiety centers. Am. J. Physiol. 225:1089-1095.

53. Sawchenko, P.E., and M.I. Friedman. 1979. Sensory function of the liver: a review. Am. J. Physiol. 236:R5-R20.

54. Donovan, C.M., M. Hamilton-Wessler, J.B. Halter, and R.N. Bergman 1994. Primacy of liver glucosensors in the sympathetic response to progressive hypoglycemia. Proc. Natl. Acad. Sci. USA. 91:2863-2867.

55. Cuneo, R.C., P.E. Hickman, J.D. Wallace, B.T. Teh, G. Ward, J.D. Veldhuis, and M.J. Waters. 1995. Altered endogenous growth hormone secretory kinetics and diurnal GH-binding protein profiles in adults with chronic liver disease. Clin. Endocrinol. 43:265-275.

56. Chiasson, J.-L., J.E. Liljenquist, B.C. Sinclair-Smith, and W.W. Lacy. 1975. Gluconeogenesis from alanine in normal postabsorptive man: intrahepatic stimulatory effect of glucagon. Diabetes. 24:574-584.

57. Stevenson, R.W., K.E. Steiner, M.A. Davis, G.K. Hendrick, P.E. Williams, W.W. Lacy, L. Brown, P. Donahue, D.B. Lacy, and A.D. Cherrington. 1987. Similar dose responsiveness of hepatic glycogenolysis and gluconeogenesis to glucagon in vivo. Diabetes. 36:382-389.

58. Groen, A.K., R.C. Vervoorn, R. Van der Meer, and J.M. Tager. 1983. Control of gluconeogenesis in rat liver cells. I. Kinetics of the individual enzymes and the effect of glucagon. J. Biol. Chem. 258:14346-14353. 